\title{
Un privilegio diplomático conflictivo en la Roma del siglo XVIII: la jurisdicción de la Corona española en el distrito del Forum Hispanicum
}

\author{
JoRge García SÁNCHEZ \\ Universidad Complutense de Madrid
}

\begin{abstract}
A diplomatic privilege as a source of conflict in Eighteenth Century Roma: Spanish Crown jurisdiction in the Forum Hispanicum district
\end{abstract}

\begin{abstract}
RESUMEN
Desde el siglo XVII, el establecimiento de una legación fija para los representantes españoles ante la Santa Sede originó numerosos conflictos con el pontificado a causa del derecho de jurisdicción real sobre el distrito de la Plaza de España, en el que aquélla se ubicaba. En el siglo XVIII este privilegio provocará una serie de rupturas diplomáticas entre la Corona y los Estados Pontificios, ya que las prerrogativas de los ministros plenipotenciarios afectaban a la soberanía del Gobierno papal. Los constantes enfrentamientos entre los guardias de la embajada y los agentes de la justicia romana dentro de la jurisdicción constituyeron una grave amenaza para la conservación del dominio español en ese sector de Roma.

PALABRAS CLAVE: Plaza de España / Diplomacia siglo XVIII / Embajada española / Santa Sede.
\end{abstract}

\section{ABSTRACT}

Since the $17^{\text {th }}$ Century, the setting-up of a permanent Embassy in Rome gave rise to many conflicts between the Spanish Monarchy and the Holy See, due to the royal jurisdiction over the Plaza de España district, the seat for the Spanish Embassy. In the $18^{\text {th }}$ Century, this privilege caused a number of diplomatic splits between the Spanish Crown and the Pope, as the plenipotenciaries rights damaged pontifical sovereignty. The continual quarrely between Embassy's guards and Roman agents inside the district were a serious threat againts the preservation of Spanish royal jurisdiction.

KEYWORDS:

Spanish Square / 18th Century diplomacy / Spanish Embassy / Holy See. 
Nuestro país no poseyó una sede estable en la que habitaran sus embajadores en Roma hasta mediados del siglo XVII. Con anterioridad éstos habían escogido como residencia palacios privados que ocupaban en alquiler, como el Orsini en Campo dei Fiori, en el que se alojó Antonio de Córdoba a principios del XVI; el palacio Altemps, en el que se acomodaron algunos de sus sucesores a mitad de dicho siglo; en el Pozzo delle Cornacchie, arrendado hacia 1587, nombre habitual con el que se reconocía la calle que discurría entre la Maddalena y Chigi; los actuales palacios Aldobrandini y Doria Pamphili, localizados en la vía del Corso y reunidos en uno solo, y el de Urbino, fueron asimismo utilizados como embajada en 1595, así como el elegido en 1603 por el duque de Villena en la Plaza Navona, el palacio De Cuppis ${ }^{1}$. Algunas de estas residencias hospedaron a más de un embajador, pero ninguna se estableció como aposento definitivo hasta 1622, momento en el que el ministro español se asentó en el Palacio Monaldeschi, ubicado en la Plaza de la Trinità dei Monti. A partir de aquí, el conde de Monrey en 1629 y el marqués de Castel Rodrigo en 1635 lo adoptaron como morada (Figs. 1-2). No

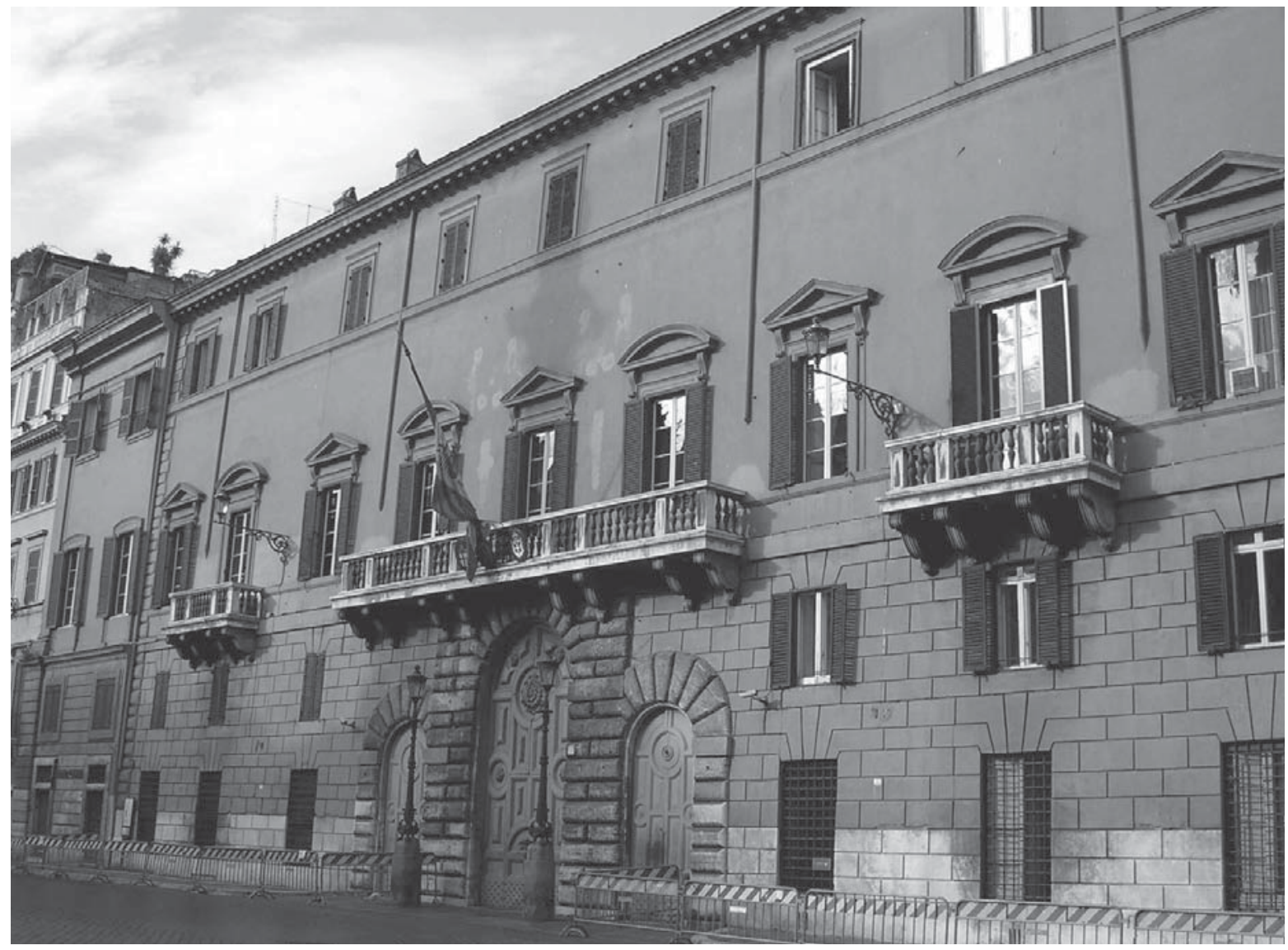

Fig. 1. Palacio de España. Foto del autor

1 Sobre estos cambios de residencia de los embajadores españoles en los siglos XVI y XVII, consúltese Salerno, L., Piazza di Spagna, Roma, 1967, p. 89; Romano, P., y Partini, P., Piazza di Spagna nella storia e nell'arte, Roma, s.f., pp. 23 y 24. Un listado de la sucesión de embajadores en los siglos XVI y XVII se encuentra en ARDUINI, A., «L'Ambasciata di Spagna presso la Santa Sede dalle origini ad oggi», L'Illustrazione Vaticana, VII, 1936, pp. 23 y 24. 


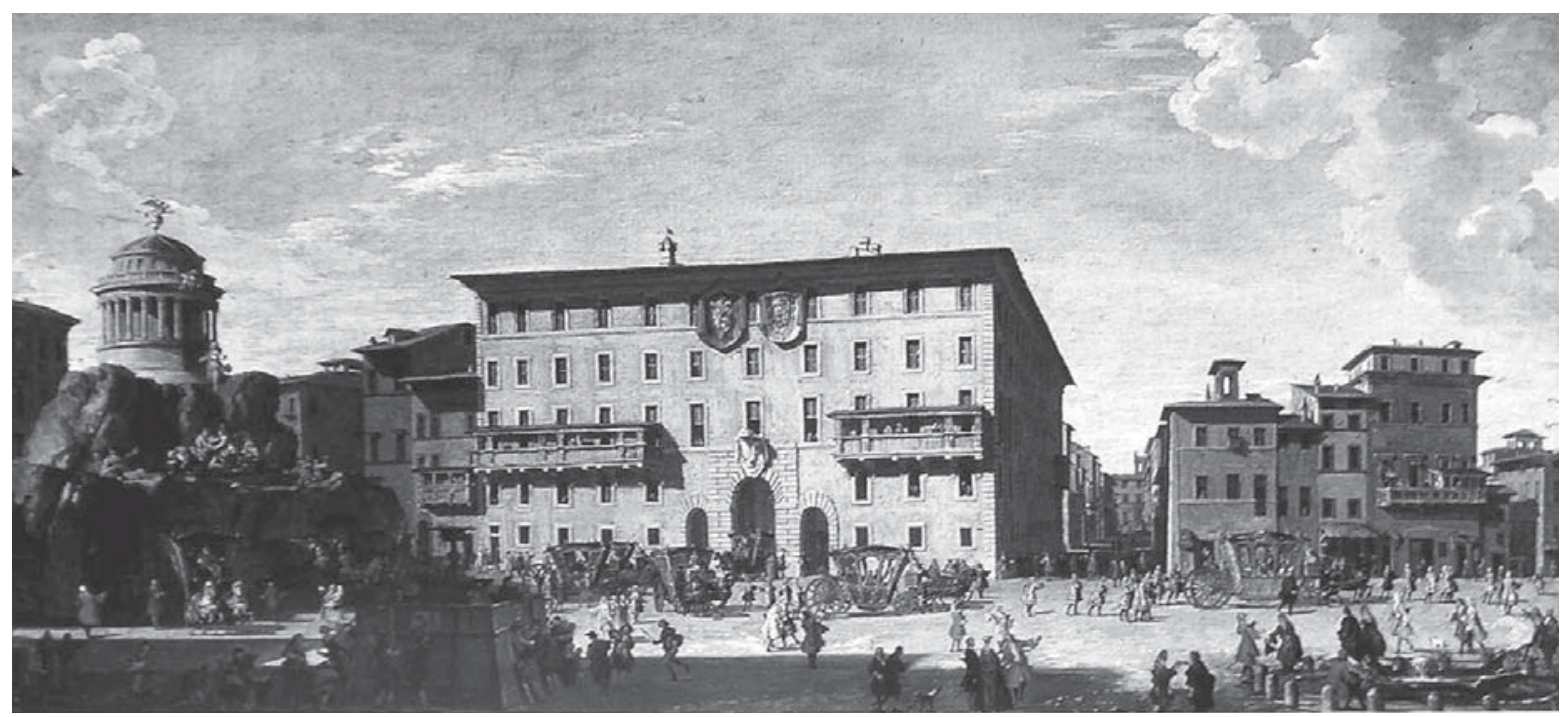

Fig. 2. El Palacio de España a comienzos del siglo XVIII. Giovanni Paolo Panini, Festa per la nascita dell'Infante di Spagna, 1727, Victoria and Albert Museum

se obtuvo sin embargo en propiedad hasta pasados 25 años, cuando Íñigo Vélez de Guevara, agente del rey Felipe IV de Austria, lo compró para la Corona de España por 22.000 escudos en la pública subasta celebrada el 25 de enero de 1647. No obstante, el proceso de la venta del palacio se prolongó hasta 1654, año en el que se fecha la última acta de traspaso. El intermediario que llevó a cabo la compra fue Bernardino Barber en calidad de pro persona nominada, es decir, como delegado de Guevara y del monarca. El instrumento de adquisición desapareció en el incendio del archivo de 1738, pero estos detalles se sabían en el siglo XIX por las memorias manuscritas de un archivero del palacio ${ }^{2}$. Con el establecimiento de una sede fija en la capital de los Estados Pontificios comenzó el derecho de jurisdicción sobre el área en la que la embajada se alzaba por parte de los embajadores españoles, quienes disfrutaban asimismo de inmunidad diplomática. La Piazza della Trinità dei Monti se convirtió en poco tiempo en la Piazza di Spagna o Forum Hispanicum (Fig. 3), denominación proveniente del palacio que en ella se alzaba y de esta potestad ejercida por los ministros de la Corona, conocida como «el franco», o localmente, libertà di quartiere ${ }^{3}$. Desde la embajada el ámbito de actuación española se extendía no sólo por la plaza adyacente, sino que abarcaba todas las calles comprendidas entre San Andrea delle Fratte y la vía del Corso; a la vista de los

2 Archivo del Ministerio de Asuntos Exteriores. Santa Sede (desde ahora, AMAE. ss.) leg. 938. Carta de José Narciso Aparici a Evaristo Pérez de Castro de 30 de octubre de 1820.

3 Acerca de la jurisdicción española en la zona se puede consultar Romano, P., y Partinı, P., Piazza... pp. 37-56; CARDILLI, L., «Feste forestieri colore», en AA. VV., La scalinata di Trinità dei Monti, Milán, 1996, pp. 219 y 220; DoNINI, A., «Transformismi architettonici: la facciata del Palazzo di Spagna a Roma in una medaglia di Pio X», Medaglia, 5, 1973, p. 83; BANDINI, C., «La giurisdizione spagnola sul rione di Piazza di Spagna nel Settecento», Atti del II Congresso Nazionale di Studi Romani, Roma, 1930, vol. II, pp. 235239; Anselmi, A., «ll quartiere dell'Ambasciata di Spagna a Roma», en CALABRI, D., y LANARO, P., La città italiana e i luoghi degli stranieri XIV-XVIII secolo, Bari, 1998, pp. 206-221; del mismo autor, II Palazzo dell'Ambasciata di Spagna presso la Santa Sede, Roma, 2001, p. 171 y ss. 


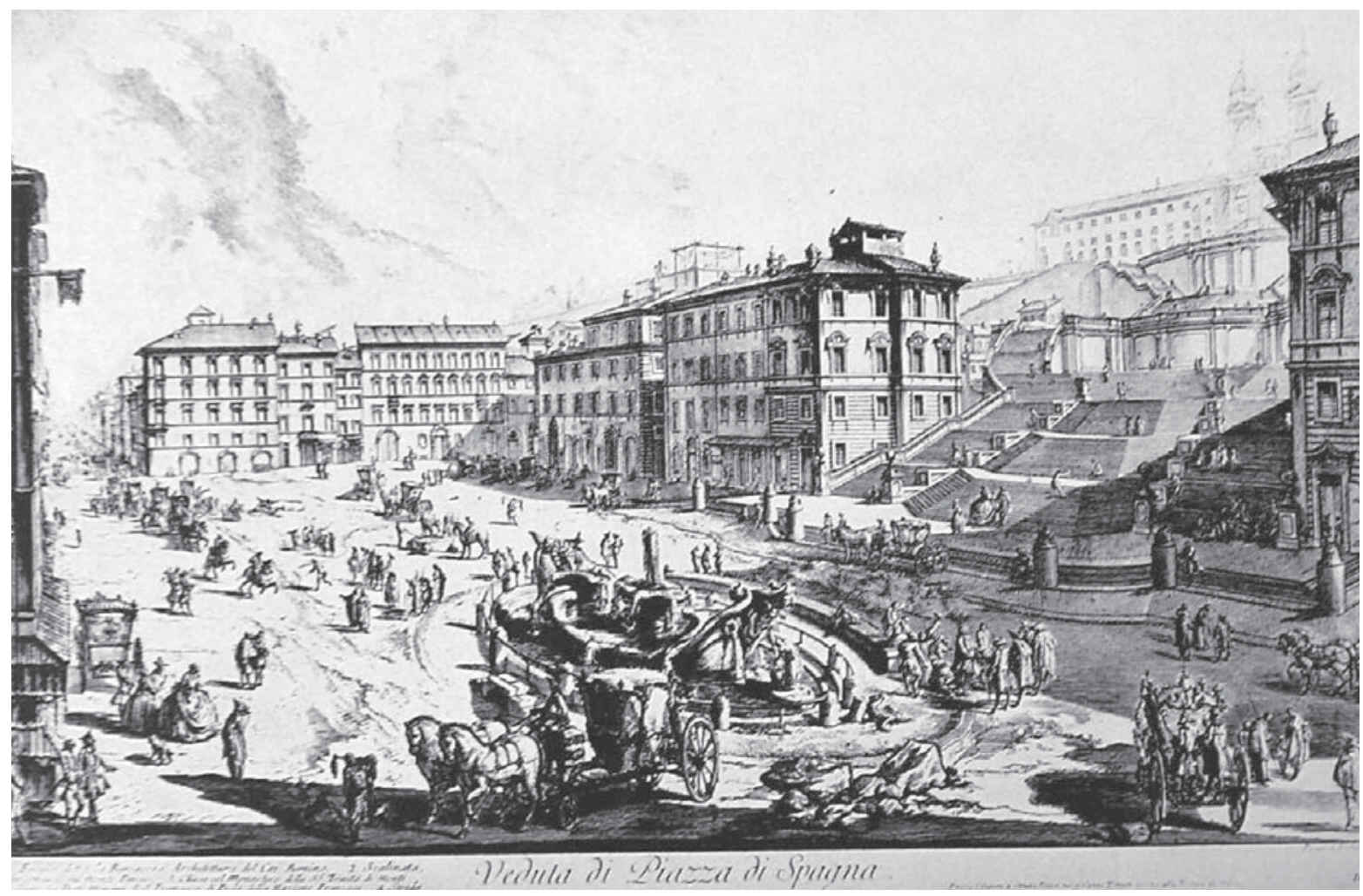

Fig. 3. Giovanni Battista Piranesi, Veduta di Piazza di Spagna, 1750

viandantes, extranjeros y autóctonos, se delimitaba la zona mediante piedras blancas con las siglas grabadas de A.D.S. (Ambasciata di Spagna).

El franco comportaba una serie de privilegios que poseía la nación española casi exclusivamente. La embajada quedaba protegida por un nutrido cuerpo de guardia, que a su vez practicaba labores policiales en el ámbito señalado, además de otro tipo de actividades que como estudiaremos, no siempre se insertaban dentro de la legalidad ${ }^{4}$. Los enfrentamientos con los espías y agentes pontificios los llamados «esbirros»- eran frecuentes, si bien en ocasiones la policía pontificia podía intervenir en el área de la embajada, aunque sólo bajo el permiso concedido por ésta. El embajador además tenía el derecho de administrar la justicia en nombre del monarca español, de practicar arrestos en el distrito del palacio y de dar asilo en su residencia a quienes quisieran evadirse de las autoridades romanas, hecho que provocaba desavenencias entre la Corona y el pontificado ${ }^{5}$. Durante siglos se intentó limitar, o incluso hacer que la monarquía española renunciase a las prerrogativas de sus embajadores en Roma, habitualmente con escaso éxito;

4 Ver BANDINI, C., «La giurisdizione...», p. 235.

5 Gracias a este privilegio de asilo del que gozaba la legación española, durante la República Romana algunos nobles como el conde Orsini pidieron alojamiento en ella para beneficiarse de la protección de la Corona y no sujetarse a las leyes del nuevo Gobierno de la ciudad, aunque en estos años los derechos del rey de España sobre el franco habían sido abolidos. AMAE. ss. leg. 369. Carta del embajador extraordinario Gabriel Durán al arzobispo de Toledo de 18 de mayo de 1798. 
Pío IV, Gregorio XIII, Sixto V o Inocencio XI, entre otros papas, habían emitido bulas condenando la regalía que detentaba España. Los periodos de mayor conflictividad en torno al distrito español, que la Santa Sede explotaba para cuestionar las prerrogativas de la Corona española, señalan a menudo las grandes crisis de las relaciones hispano-italianas durante el siglo XVIII. Uno de estos enfrentamientos sirvió de prólogo a la grave ruptura de los lazos diplomáticos entre los dos estados en 1718, motivada por el constante problema de las levas de soldados practicadas a la fuerza en Roma por la Monarquía española, y por el mantenimiento de un arsenal escondido en la Villa Medici para la eventual defensa de la sede de la embajada, sobre el cual vino en conocimiento la Santa Sede 6 . En el verano de 1716 dos disputas en el franco provocaron su circunstancial suspensión en ese año: en la primera de ellas el barrichelo, jefe de la policía pontificia, condujo a un grupo de esbirros dentro de la jurisdicción, aparentemente con objeto de administrar la justicia del Gobierno de Clemente XI, siendo expulsados por la guardia de palacio ${ }^{7}$. En la segunda, ocurrida la noche del 13 de septiembre, una turba de romanos penetró en la Plaza de España festejando la reciente victoria imperial contra los turcos con el acompañamiento de tambores; los soldados españoles interrumpieron el paso a la muchedumbre, y ante su resistencia, la hicieron retroceder a golpes fuera de las calles del distrito. Los mecanismos de la diplomacia española y papal se pusieron en el acto en funcionamiento, requiriendo aquélla a través del embajador Troyano Acquaviva una satisfacción por lo sucedido, que se expresase el dolor del soberano por esta clase de lances injustificados, y que se emprendieran diligencias para conocer la parte jugada por el Gobierno en todo ello ${ }^{8}$. A su vez, éste mantuvo una doble postura, pues a pesar de presentar oficialmente sus disculpas, dictó un bando condenando a la horca a diez guardias de palacio, si bien poco después rectificó su posición, y a instancias del Santo Padre se ofrecía al ministro de Felipe $\checkmark$ la posibilidad de despedir a los citados soldados, concediéndoles salvoconducto para abandonar la Urbe, y lo que es más importante, se demandó que los agentes del pontífice pudieran transitar libremente por la Plaza de España. La respuesta de Acquaviva resulta desconcertante, ya que actuando sin el respaldo de la legitimidad real convino en este último punto, a condición de que lo mismo se verificase en el resto de las legaciones. Felipe $V$ desaprobó los pasos adoptados por su representante en Roma, le reprochó la cesión de derechos que competían en exclusividad al monarca, y le comunicó que hiciera saber al Gobierno pontificio que se rechazaban los salvaconductos y que se castigaría a los esbirros que atravesaran la jurisdicción, así como que reincidiese en la petición de satisfacciones, pues-

${ }^{6}$ Moli Frigola, M., «Viajeros españoles en Nápoles», en Kanceff, E., y Rampone, R., Viaggio nel sud. Verso la Calabria, Biblioteca del viaggio in Italia 41, Centro Interuniversitario di Ricerche sul «Viaggio in Italia», 1992, p. 235.

7 A consecuencia de esta acción de la justicia pontificia el mariscal de campo de los ejércitos del rey y gobernador de Portolongone, Jacinto del Pozobueno, recibió la orden de poner sus hombres a disposición del embajador Troyano Acquaviva en el caso de que este solicitase refuerzos desde Roma para proteger la legación.

8 AMAE. Ss. leg. 166. Cartas de Juan de Elisondo al cardenal Acquaviva de 13 de julio, 26 de octubre y 9 de noviembre de 1766 . 
to que las ofrecidas obviamente no le habían complacido ${ }^{9}$. Durante los meses iniciales de 1717 se sucedieron las reclamaciones del cardenal Acquaviva en este sentido, obteniéndose tan sólo banales excusas de Clemente XI de que su actitud no pretendía redundar en perjuicio de la Corona de España, sino en beneficio del mantenimiento de la soberanía en su Corte. Con esta partida finalizada en tablas los dos gobiernos se dieron por satisfechos hasta la mencionada crisis de 1718 .

Mayores repercusiones tuvo el trance que afrontó el cardenal Acquaviva, entonces aún ministro de la embajada, cuando se cortaron las relaciones diplomáticas entre la Santa Sede y España durante un año, entre los meses de mayo de 1736 y 1737. La ofensiva del duque de Montemar en territorio italiano contra las tropas imperiales había dado lugar a que en Roma y las Estados Pontificios los enganches del bando español practicasen reclutamientos de forma abusiva, por los cuales nuestro país era bien conocido desde el XVII: un chascarrillo extendido en la segunda mitad de ese siglo advertía a los jóvenes romanos de los riesgos que implicaba pasearse por la Plaza de España, donde podían ser enrolados a la fuerza en las filas del ejército español en épocas de escasez de soldados ${ }^{10}$. El 23 de marzo de 1736, el tumulto suscitado por los rumores de las prácticas ilícitas de los enganches de Felipe $\mathrm{V}$ en el barrio de Trastevere desembocaron en desórdenes a lo largo de toda la ciudad, en los que las tropas pontificias dejaron libertad a la embravecida población romana para manifestar su descontento hasta en la misma Plaza de España, donde los soldados de la embajada hicieron fuego contra la multitud ${ }^{11}$. Según relata el erudito Francesco Valesio en su Diario di Roma, la primera noche de la revuelta 150 españoles armados con dos cañones y 300 granadas hicieron guardia delante de la legación, a la cual se había protegido con trincheras y barricadas. Al entrar la muchedumbre en la plaza, y comenzar los disturbios gritando vivas al emperador y lanzando piedras a los soldados, éstos reaccionaron disparando sus arcabuces, resultando tres personas heridas de bala y una cuarta debido a un bayonetazo en el estómago ${ }^{12}$. En términos bien diversos narraba los hechos el viajero español autor de El Passeo de Roma concluido en Napoles, (el cual en 1736 se instaló en Roma con la intención de dedicarse al arte del dibujo, y que sin embargo tuvo que sobrevivir con el oficio de cocinero), al resaltar la cobardía de los trasteverinos, quienes, «en llegando al palacio de nuestro soberano con sólo cuatro hombres y un cabo, huyeron precipitadamente y aun no han vuelto, bien que los esperaban otro día» ${ }^{13}$. Por mandato de Felipe $\mathrm{V}$, el cardenal Acquaviva dio la orden de

9 Íbidem. Cartas de Juan de Elisondo al cardenal Acquaviva de 23 de noviembre de 1716 y 1 de febrero de 1717.

10 El texto del chascarrillo decía: «Hai inteso, Hai inteso, non passà a piazza di Spagna ché sarai preso». Romano, P. y Partini, P., Piazza..., p. 52.

11 Consúltese sobre este incidente Pérez Estévez, R. M. ${ }^{a}$, y González Martínez, R. M. ${ }^{a}$, Pretendientes y pícaros españoles en Roma. Siglo XVIII, Valladolid, 1992, p. 20 y ss.

12 VALESIO, F., Diario di Roma. Libro nono e libro decimo. 1729-1736, Milán, 1979, vol. V, p. 849 y ss. Los diarios de Francesco Valesio, que contienen una crónica detallada de la vida social, religiosa, política y artística de la Roma de la época, se extienden de 1700 a 1711, y de 1724 al 1742.

13 Pérez Estévez, R. M. a y González Martínez, R. M. a , Pretendientes..., p. 100. 
partir de Roma a todos los nacionales presentes en la ciudad, incluidos los eclesiásticos, en un plazo de doce días, y veinte para los Estados Pontificios, bajo la amenaza de confiscaciones y multas; tampoco permanecieron en la Ciudad Eterna los miembros de la guardia de palacio, dejándose encomendada su custodia a una persona de la confianza de Acquaviva, que como le habían indicado desde la Corte, no debía ser ni español, ni vasallo del rey de las Dos Sicilias ${ }^{14}$. En respuesta a la iniciativa de Felipe V, el 11 de mayo de 1736 la Congregación de cardenales decretaba la suspensión de los cargos de aquellos religiosos que salieran de la ciudad sin el consentimiento de dicha institución, y aunque se especificaba que la ordenanza iba dirigida a los clérigos de cualquier nacionalidad, la alusión a los españoles resultaba patente. Acquaviva marchó a Nápoles ese mismo mes protegido por una fuerte escolta de soldados españoles, de donde no regresaría hasta marzo de 1737, cuando el conflicto se hallaba en vías de negociación, en las cuales la franquicia española sobre el Forum Hispanicum se mantuvo indemne.

Hacia mediados de siglo todavía se mantenía vigente el malestar de la población romana suscitado por las levas forzosas mediante las cuales se nutrían las tropas españolas, y en los periodos en que se reavivaba el antagonismo del Borbón con la Santa Sede se manifestaba como excusa para desencadenar los sentimientos antiespañoles (Fig. 4). En abril de 1748 la desaparición de un muchacho

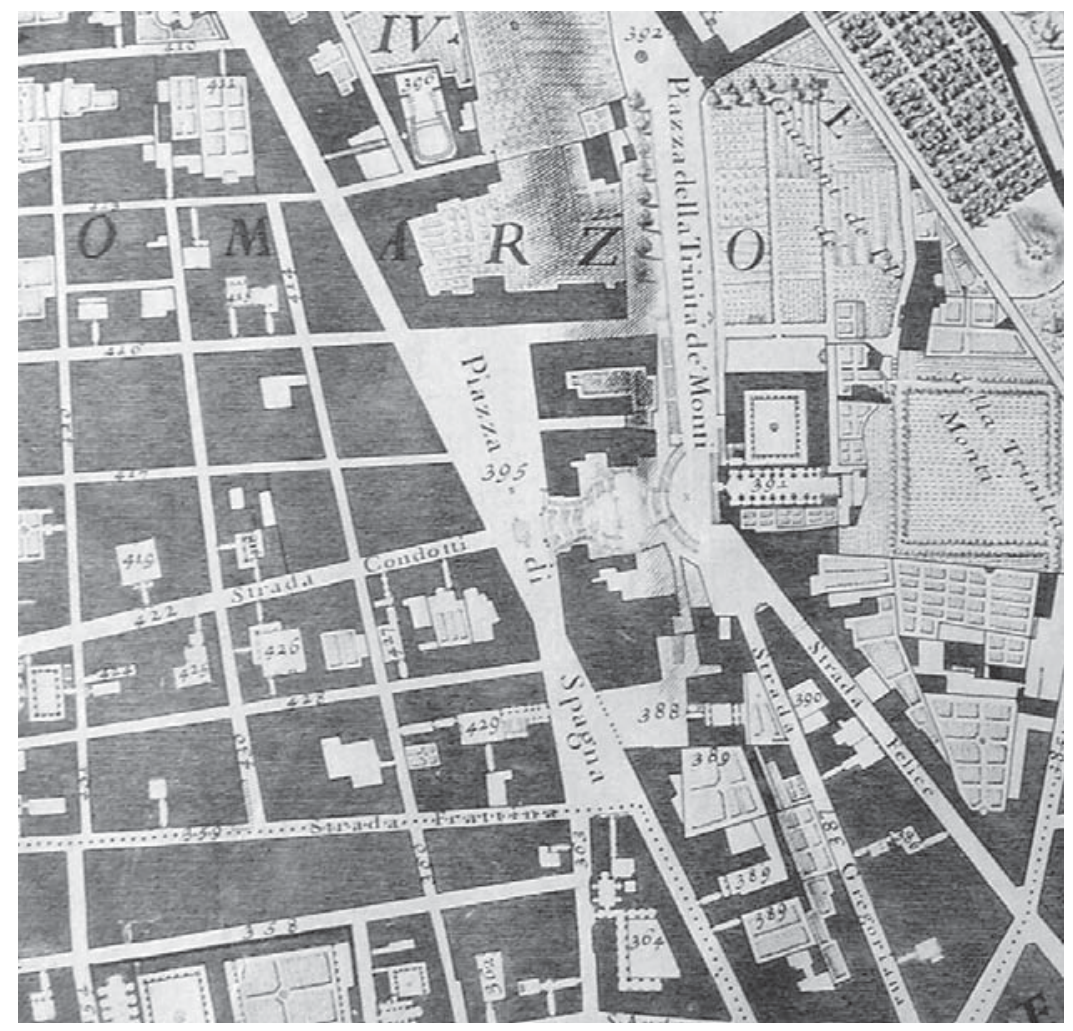

Fig. 4. Área de la Plaza de España a mediados del siglo XVIII. Giambattista Nolli, Pianta di Roma, 1748

${ }_{14}$ AMAE. ss. leg. 185. Carta de José Patiño al cardenal Acquaviva de 27 de mayo de 1736. 
romano se creyó un típico caso de reclutamiento a la fuerza, lo cual despertó una serie de voces que rápidamente se difundieron y se hicieron oír por toda la ciudad del Tíber. La justicia papal inició las investigaciones oportunas para descubrir a los agitadores que hacían circular estos rumores, y sometió a penas físicas a cuatro hombres y a un quinto lo condenó a galeras ${ }^{15}$. El teniente coronel del ejército real Julio Devon, que por entonces examinaba la posibilidad de enrolar gentes nuevamente en Roma, hubo de abandonar la Urbe a la vista de las dificultades que planteaban estos acontecimientos. Fruto del clima de animadversión contra España fueron algunas hostilidades que sufrieron súbditos de dicha nacionalidad: en junio de 1748 varios mendigos españoles fueron insultados y apedreados por una cuadrilla de romanos ante las puertas de Santa María la Mayor, siendo castigado uno de los agresores con el suplicio de la cuerda ${ }^{16}$; en ese mismo mes un guardia destacado en la Fontana di Trevi entró en el franco en persecución de un joven pistola en mano, y detenido e interrogado por un servidor de la embajada acerca de sus intenciones no dudó en descargar su arma sobre él, si bien la pólvora no prendión ${ }^{17}$. En consecuencia unas noches después se le sometió a la cuerda en la vía del Corso, iluminando su tormento la luz de las antorchas, pena que también se aplicó a un frutero que había injuriado a un español vilipendiando su origen.

Los obstáculos al reclutamiento de la monarquía borbónica en la Corte romana a final de siglo se iban a superar precisamente en el ámbito de la propia jurisdicción. La labor de la guardia no resultaba fácil en un distrito en el cual no eran extraños los desórdenes y las reyertas, especialmente en la segunda mitad del siglo XVIII, cuando la concentración de viajeros extranjeros en torno a la Plaza de España (denominados «inghilesi» en general por la mayor afluencia de aristócratas británicos que efectuaban el Grand Tour) empezó a atraer a gran cantidad de mendigos y pícaros deseosos de sacar provecho de estos visitantes. El marqués de Grimaldi (embajador de 1777 a 1784) comunicaba al conde de Floridablanca que desde su llegada le había sorprendido la profusión de españoles que se contaban entre esos truhanes, y que en los límites del franco daban rienda suelta a su libertinaje, cometiendo toda clase de excesos ${ }^{18}$; sugería por ello que procurándose la conformidad del Gobierno de Roma, se podría seleccionar a los más adecuados para enrolarlos en las tropas del rey y embarcarlos en las naves comerciales catalanas que abandonaban Italia con asiduidad. Floridablanca apoyó este proyecto concretando que en el caso de los desertores además se les concedería el indulto, si bien no se debía hacer pública esta gracia, ni notificársela a los interesados ${ }^{19}$. Muchos de los indeseables que pu-

15 AMAE. ss. leg. 311. Cartas de Alfonso Clemente de Aróstegui a José de Carvajal y Lancaster, y al marqués de la Ensenada de 13 de junio de 1748.

16 íbidem. Carta de Alfonso Clemente de Aróstegui a José de Carvajal y Lancaster de 1 de agosto de 1748.

17 Íbidem. Carta de Alfonso Clemente de Aróstegui a José de Carvajal y Lancaster de 27 de junio de 1748.

18 Archivo General de Simancas (a partir de ahora, AGS.) Estado. leg. 4994. Carta del marqués de Grimaldi al conde de Floridablanca de 13 de mayo de 1779.

${ }_{19}$ AMAE. Ss. leg. 350. Carta del marqués de Grimaldi al conde de Floridablanca de 24 de junio de 1779. 
lulaban por la Plaza de España se presentaron voluntariamente en la legación para ser repatriados: Manuel Quintanilla, un madrileño de diecinueve años que había desertado de la Marina, partía hacia España en el verano de 1779 tras beneficiarse del auxilio económico de la embajada durante un mes. Muchos otros, como Pedro Pujol, comparecieron ante las autoridades españolas para servir en las armas de Carlos III después de haber cometido un asesinato, del cual preferían no responder ante los tribunales locales ${ }^{20}$. El largo viaje hasta la Península Ibérica suponía una buena oportunidad para evadirse y no cumplir con el arriesgado compromiso adquirido; así, de veintitrés reclutas que partieron hacia Alicante a finales de 1779 en una nave genovesa únicamente cinco fueron puestos a disposición del gobernador de la ciudad, dado que el resto habían huido en Livorno. Curiosamente el mencionado barco transportaba una importante carga artística destinada a la Academia de San Fernando de Madrid, la colección de vaciados escultóricos de yeso que el pintor neoclásico Mengs había donado al soberano Borbón ${ }^{21}$.

El número de guardias a cargo del embajador varió durante el siglo XVIII: hacia 1736 se hallaban empleados en la defensa del Palacio de España un capitán, un sargento y tres soldados, y de 1747 existen referencias que mencionan a un capitán, un sargento, tres cabos con librea y siete sin ella. En épocas especialmente problemáticas se trasladaban tropas regulares del sur de Italia, como en 1709, cuando doscientos hombres se acuartelaron en la Plaza de España, o en 1736, fecha en la que la protección de Acquaviva requirió la presencia de un considerable número de soldados. En 1798, año en que la República Romana sostenida por el ejército revolucionario abolió el franco, el palacio perdió a la reducida milicia que aún lo custodiaba, siendo el detonante el comportamiento de éstos durante la ocupación francesa. El 9 de noviembre treinta soldados de la guardia nacional detuvieron dentro de la legación a Rafael Piñero ${ }^{22}$ y Vicente Cañizo, acusados, según informaba el Ministro de Justicia y de la Policía al embajador extraordinario Gabriel Durán, de «propalare delle notizie allarmanti, e tendenti ad eccitare nell'animo dei deboli l'alienazione dalla Repubblica». Durán, con el propósito de que el palacio de la embajada no sufriera afrentas similares a la de esta irrupción, arregló la salida de Roma de Raimundo Mercader, el último guardia de servicio, y cuando después de dos semanas de encarcelamiento se puso en libertad a sus dos compañeros, les prohibió que durmieran en el palacio una sola noche, y les instó igualmente a partir ${ }^{23}$. Dos conserjes sin divisa se ocuparon de abrir y cerrar las puertas del palacio a las horas acostumbradas hasta que se produjo la abolición de la República Romana.

20 AGS. Estado. 4994. Carta del marqués de Grimaldi al conde de Floridablanca de 26 de agosto de 1779.

21 Negrete Plano, A., «La colección de vaciados de Mengs», Academia, 92-93, 2001, pp. 9-31.

22 Previamente, en el verano de ese mismo año de 1798, Piñero, cuyas labores se limitaban ya a proteger el Palacio de España, había herido con su sable a dos o tres romanos en el barrio de Trastevere por cantar un himno revolucionario francés, la Carmagnòla, agresión por la que se le formó un proceso. AMAE. ss. leg. 369. Carta de Gabriel Durán a Francisco de Saavedra de 25 de julio de 1798.

${ }_{23}$ Íbidem. Carta de Gabriel Durán a Francisco de Saavedra de 25 de noviembre de 1798. 
Las pendencias ocasionadas por el excesivo celo de los guardias en salvaguardar la inviolabilidad del franco, a veces propias de una novela de Alejandro Dumas, aparecen frecuentemente en la documentación consultada. Los incidentes con los esbirros papales, los lacayos, sirvientes y escoltas de aristócratas, ministros extranjeros y prelados romanos se hallaban a la orden del día, pese a las amenazas y providencias dictadas por los embajadores españoles para evitar los escándalos. La réplica del ministro de la legación a las vulneraciones del franco solía conllevar la reclamación al pontífice de satisfacciones públicas y la aplicación de penas a los culpables, consistentes en destierros, condenas a trabajos forzados y sobre todo a la tortura de la cuerda, intercediendo ocasionalmente los embajadores por los infractores tras haberlos incriminado si consideraban que la transgresión no era de gran alcance. Por otro lado los guardias del Palacio de España recibían asimismo puniciones si procedían sin la previa autorización del ministro del rey, algo común en la historia de la inmunidad del Forum Hispanicum. Al ponerse al frente de la legación en 1726 el cardenal Bentivoglio se habían multiplicado tanto los abusos de poder por parte de los soldados del palacio que el nuevo ministro plenipotenciario solicitaba a la Corona una real orden en la que se le dotase de un poder absoluto sobre aquéllos para contener sus excesos, y la capacidad de devolverlos a sus regimientos en caso de desobediencia, incorporando a otros menos impul$\operatorname{sivos}^{24}$. En apenas unos pocos días del mes de noviembre los guardias habían apaleado al cochero del cardenal Marini, primero frente a la puerta de la residencia de su señor, y después en la caballeriza donde buscaba refugio, a un mercader francés que se había parado a echar un vistazo del interior de la embajada, y a un postillón con librea del cardenal Alessandro Albani, que según se excusaban los agresores, había hablado mal de Bentivoglio. A petición de éste, el conde Aldobrandini, embajador de Bolonia, notificaba a Albani el disgusto del ministro por lo acaecido, asegurándole que los culpables se encontraban bajo arresto, y que de haberse tratado de sus propios lacayos, su actuación habría sido más enérgica, disculpa que no evitó que Albani elevase una querella al Gobierno pontificio ${ }^{25}$. Años más tarde sería el embajador interino Alfonso Clemente de Aróstegui quien decidiera trasladar directamente al coronel del regimiento de Castilla su deseo de que enviara a dos de sus soldados para sustituir a dos guardias de palacio, arrestados por confiscar las pistolas de un servidor del príncipe Chigi y golpearle con sus bastones, comportamiento que Aróstegui achacaba a la despreocupación e imprudencia que el largo tiempo de servicio en el palacio provocaba en estos hombres $^{26}$.

El cardenal Bentivoglio incluía asimismo en su demanda al rey la facultad de controlar al capitán de la guardia - función desempeñada entonces por el «violento

\footnotetext{
${ }^{24}$ AMAE. ss. leg. 289. Carta del cardenal Bentivoglio al marqués de la Paz de 9 de noviembre de 1726.

25 Íbidem. Carta del cardenal Bentivoglio al marqués de la Paz de 13 de noviembre de 1726.

26 AMAE. ss. leg. 310. Carta de Alfonso Clemente de Aróstegui a José de Carvajal y Lancaster de 8 de junio de 1747.
} 
e impetuoso» Fernando Fernández Guerrero-, que intervenía en los asuntos de la Plaza de España arrogándose potestades privativas del embajador, amén de arbitrar actividades ajenas al estricto marco de lo legal ${ }^{27}$. Con permiso de Guerrero un pintor organizaba en su negocio juegos de azar en los que según un escandalizado Bentivoglio, las riñas y blasfemias eran frecuentes, por lo cual le había obligado a cerrar ${ }^{28}$. Igualmente Guerrero se valía del nombre del religioso para desalojar de las viviendas de la jurisdicción a quien no le placiese, y protegía a las prostitutas y a las mujeres de conducta escandalosa que entablaban relaciones con los guardias del palacio, muchas de ellas casadas, y cuyos maridos, por miedo a las represalias de Guerrero, no denunciaban ${ }^{29}$; éste había logrado soslayar las reclamaciones del cardenal vicario acerca de que se expulsara a esas mujeres públicas hasta que Bentivoglio terció en el asunto. El puesto de capitán de la guardia, instituido por José de Molinés entre los conflictivos años de 1709 y 1716 para afianzar la prerrogativa española del mantenimiento del orden público en el barrio de la legación ${ }^{30}$, proporcionaba a su detentor una cómoda posición de mando, por lo que se convirtió en un destino muy deseado por los oficiales del ejército español, y de difícil obtención. En 1775 el conde de Floridablanca desestimaba la candidatura de Carlos María Canales, nacido de las relaciones entre Solimán, bajá de Esmirna, y una mujer de origen catalán, entendiendo que en las tropas del rey podría elegir entre militares de mayor mérito. Pocos años después el diplomático José Nicolás de Azara, contrario por principio a la existencia de este cargo, recomendó negativamente la solicitud de promoción de sargento de la guardia a capitán de Francisco Sarmiento por idénticas razones ${ }^{31}$. Al parecer Bentivoglio consiguió meter en cintura a su díscolo subalterno, ya que de ahí en adelante lo encontramos cumpliendo fielmente con las instrucciones del cardenal, que éste recibía a su vez de Madrid, consistentes en evitar cualquier conflicto en la jurisdicción mediante el recurso de echar a los «malvivientes», prohibiendo los juegos, y erradicando los pecados y

27 Del mismo modo que el capitán y los soldados de la guardia, otros servidores de la Corona española empleados en la embajada cumplían con sus obligaciones de salvaguardar el franco de una forma particularmente despótica y abusiva. Por ejemplo, de comienzos del XVIII son dos noticias relativas a actos de violencia cometidos por el ayudante de la secretaría de la embajada: en 1704 junto a otro español asestó diez puñaladas a un supuesto esbirro que pasaba por la vía de' Bernini, que tras ser confesado por un sacerdote en medio de la calle, fue trasladado a un hospital de nombre poco alentador, San Giacomo degli Incurabili. Un año después dicho ayudante interrogó a un valenciano que vendía estampas del emperador en la Plaza de España, a quien también mandó a San Giacomo degli Incurabili tras hacer que se le paleara en la cabeza y los brazos. VALESIO, F., Diario di Roma. Libro quinto e libro sesto. 1704-1707, Milán, 1978, vol. III, pp. 60 y 393.

28 Tal vez a causa de este tipo de comportamientos el cardenal Bentivoglia ordenó en 1727 que se cerraran en la jurisdicción los negocios de un carpintero, un tornero y un carnicero, y que en el Diario de Valesio se interpretaba como el deseo de un «uomo alquanto stravagante» de no escuchar ningún estrépito en torno a su demora. Valesio, F., Diario di Roma. Libro settimo e libro ottavo. 1708-1728, Milán, 1978, vol. IV, p. 844.

${ }^{29}$ Bentivoglio también resaltaba en sus misivas a la Corte la vergüenza de que Guerrero permitiese que la amancebada de un monje capuchino habitase bajo las mismas ventanas del palacio. AMAE. Ss. leg. 289. Carta del cardenal Bentivoglio al marqués de la Paz de 16 de noviembre de 1726.

30 Ver Anselmi, A., «ll quartiere...», p. 181.

31 AGS. Estado. leg. 4998. Carta de José Nicolás de Azara al conde de Floridablanca de 23 de diciembre de 1784. 
las conversaciones «poco honestas» de la Plaza de España ${ }^{32}$. Víctima de la conservación de la moralidad del quartiere fue la viuda conocida como la Vizcontina, a quien se arrojó de su casa por reunir en ella la noche del 25 de noviembre de 1729 a un animado grupo de hombres y mujeres «de distintas calidades» en una velada que se prolongó hasta la mañana. Como se puede observar, acabar con el juego y alejar a las personas de costumbres relajadas fueron dos ocupaciones habituales en la administración de la justicia en el franco por parte de los plenipotenciarios españoles del XVIII. El juego de la lotería se veta a partir de 1725, fecha en la que el pontífice rogó al soberano Felipe $V$ que le transmitiese esa voluntad personal a su representante en Roma, al igual que él había comunicado a los cardenales que aconsejaran a sus domésticos y a las amistades de su entorno que se abstuvieran de practicar dicho entretenimiento ${ }^{33}$. Desde los primeros años del siglo XVIII se registran detenciones motivadas por jugar a las cartas tanto en lugares públicos como en residencias privadas, y a menudo sin consideración a la extracción social del infractor (Fig. 5). En 1704 siete jugadores que apostaban en la hostería de la Barcaccia, ubicada en la Plaza de España, endosaban los grilletes, y en 1737 el barón Torretti, de origen alemán, sufría un breve encarcelamiento por jugar al faraón en su casa, donde asistían numerosos extranjeros; la posesión de una cédula del rey de Portugal le valió la libertad bajo promesa de abandonar la ciudad en el plazo de tres días ${ }^{34}$. Antonio Nescio, sorprendido igualmente en su casa con las

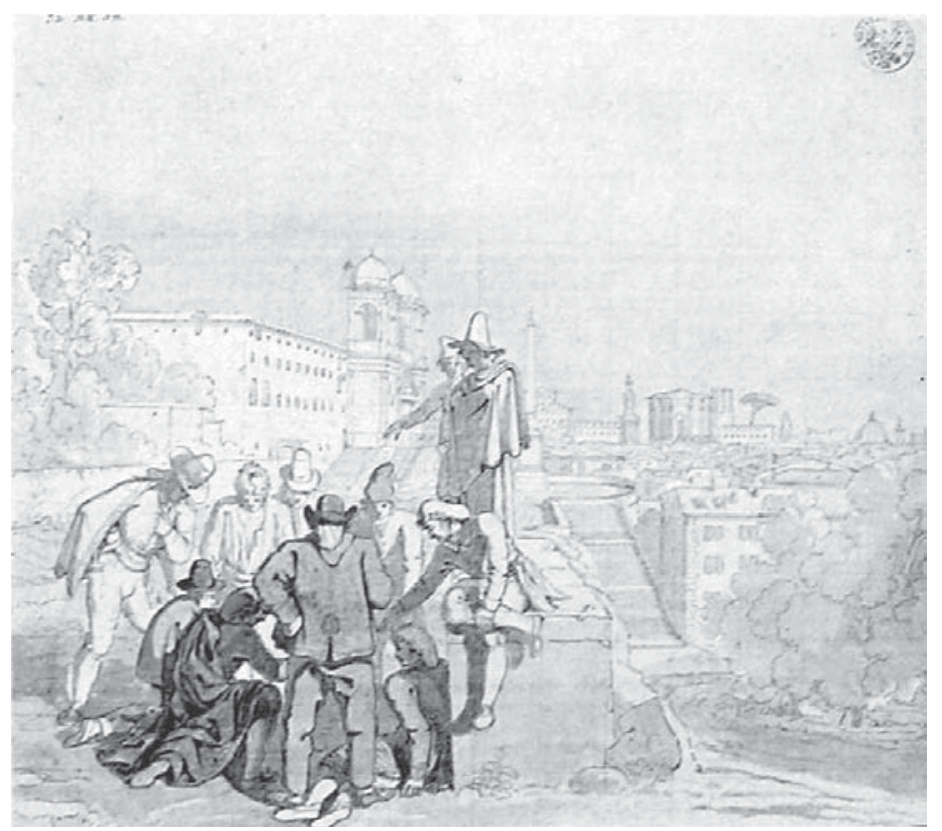

Fig. 5. Karl Friedrich Schinkel, Jugadores cerca de la iglesia de la Trinità dei Monti, c. 1803

32 AMAE. ss. leg. 179. Carta del marqués de la Paz al cardenal Bentivoglio de 1 de mayo de 1729.

${ }_{33}$ AMAE. ss. leg. 287. Carta del embajador Félix Cornejo al marqués de Grimaldo de 8 de septiembre de 1725.

34 Valesio, F., Diario di Roma. Libro undicesimo. 1737-1742, Milán, 1979, vol. VI, p. 41. 
cartas en la mano, eludía sin embargo la prisión por hallarse al servicio del emperador. Un bando del Gobierno papal condenaba asimismo el juego de la petanca en las vías públicas, y por la determinación de hacer respetar dicha disposición en el área de la Plaza de España se produjo en 1780 un altercado que derivó en un pequeño choque diplomático. Un guardia de palacio se había acercado a un grupo de jugadores que lanzaban las bolas, entre los que se encontraban dos soldados del papa que no portaban el uniforme, porque como escribía el anónimo escritor de El Passeo de Roma concluido en Napoles, practicar este pasatiempo era una de las aficiones favoritas entre las filas del ejército pontificio ${ }^{35}$. Interpelados por el español, aquéllos respondieron con chanzas e insultos, para lanzarse finalmente sobre él cuando trataba de imponerse desenvainando su espada. Advertidos del tumulto los demás guardias italianos acuartelados en la vecina calle Fratina acudieron en gran número para ayudar a sus compañeros, derribando al español y propinándole con los fusiles una brutal paliza, después de la cual lo arrastraron hasta su cuarte ${ }^{36}$. Enterado de lo ocurrido Azara protestó ante el secretario de Estado, quien ordenó arrestar a tres de los soldados que habían tomado parte en la pendencia y prometió al embajador que aplicaría castigos ejemplares. Puesto al corriente de lo sucedido, Carlos III dirigió una misiva a Azara conminándole a que además de las penas que sufrirían los culpables debía exigir en su nombre la retirada del cuartel a otra zona de Roma, y la colocación de un cartel en la calle en la que se habían desarrollado los hechos en el que se anotara: «Hasta aquí llega la jurisdicción del Palacio de España». En atención a la preocupación que el Papa había dedicado a este asunto el monarca Borbón hubo de contentarse únicamente con la expulsión del ejército de cinco de los soldados y la condena a tres años de trabajos forzosos de otro. Azara le resumía a Floridablanca la situación del franco una vez resuelto este trance: «la jurisdicción se respetaba entonces más que nunca, y la tolerancia nacida en los últimos años a que las patrullas pontificias se paseasen por ella quedaba completamente revocada ${ }^{37}$ ».

Toda pretensión del Tribunal del Vicariato de inmiscuirse en el espacio de actuación de la autoridad del embajador debía ir forzosamente acompañada de una instancia formal en la que se expusieran los motivos y se requiriese la licencia oportuna. A tenor del estado de las relaciones políticas y diplomáticas entre la Corona española y la Santa Sede la inflexibilidad del ministro plenipotenciario en acceder a las demandas que recibía y la intrusión ilegítima de los esbirros del Papa en el franco aumentaban cuantitativamente. Anecdóticamente se cuenta que en

35 «Los soldados, amigo mío, que están en Roma, le respondí, no son del Papa sino de la papa [...] Estos son soldados de aguja y lezna, no conocen más campaña que las tiendas donde trabajan, soldado una hora y zapatero todo el día. Son bien dispuestos para asaltar un horno o un barril de vino, son buenos para la paga y no para la centinela [...] Sus campañas son el juego de bolas, la estirpacion de folletos o cuartillos y el destrozo de las pañotas». Pérez Estévez, R. M. a, y González Martínez, R. M. ${ }^{a}$, Pretendientes..., p. 99.

${ }^{36}$ AGS. Estado. leg. 4994. Carta de José Nicolás de Azara al conde de Floridablanca de 17 de agosto de 1780.

37 Íbidem. Carta de José Nicolás de Azara al conde de Floridablanca de 12 de octubre de 1780. 
tiempos del embajador Molinés (1709-1716) el cardenal vicario Carpegna le pidió permiso para arrestar a dos jóvenes amantes que se ocultaban en un domicilio de la Plaza de España, a lo cual consintió aquél, bajo el requisito de que ninguno de sus agentes se introdujera en el quartiere; la sorpresa de Carpegna fue todavía mayor cuando ante su lógica réplica de que ese supuesto resultaba imposible monseñor Molinés declaró que no se responsabilizaba si sus doscientos soldados bastoneaban o dañaban a algún esbirro ${ }^{38}$. Ya en los años iniciales del siglo XIX estas instancias se multiplican en la documentación de archivo (y ahora dirigidas también por particulares al ministro español, y no tan sólo por el cardenal vicario), siempre relativas a lances muy diversos, desde arrestos y expropiaciones de morosos, hasta quejas hacia vecinos que arrojaban sus desperdicios a través de la ventana, cayendo sobre los transeúntes ${ }^{39}$. La captura fuera de la jurisdicción de ciudadanos españoles en la Urbe por mandato del Tribunal del Vicariato venía habitualmente avisada al Palacio de España, y se verificaba con la presencia de algún representante de la Corona ${ }^{40}$. La literatura también aporta ejemplos del comportamiento de los ministros de la legación en caso de que existiera el deseo del Gobierno pontificio de prender a alguien que se ocultarse en la zona englobada en el franco. En 1744, un joven Giacomo Casanova, que en aquel momento ejercía de secretario del cardenal Troyano Acquaviva, mantenía la siguiente conversación con su amigo y protector el abate Gama:

«Pocos días después, mientras me paseaba con el abate Gama por la Villa Médicis, me dijo de forma deliberada que aquella noche se celebraría una ejecución en la Plaza de España.

-Vendrá el bargello o su teniente a ejecutar alguna ordine santissimo o a visitar alguna casa sospechosa para llevarse a alguien que no se espera nada.

— ¿Cómo lo sabéis?

—Debe de saberlo Su Eminencia, pues el Papa no osaría inmiscuirse en su jurisdicción sin pedirle permiso antes.

- ¿Y se lo ha dado?

- Sí; esta mañana ha venido a pedírselo un auditor del Santo Padre.

— ¿Pero nuestro cardenal hubiera podido negárselo?

38 Salz-Pardo, M., «Huellas de los españoles en Roma», Historia y Vida, 44 (1971), p. 81.

39 Véase por ejemplo AMAE. ss. leg. 787. Exp. 8. Carta de Franco y Vincenzo Mignarelli a Antonio Vargas y Laguna de julio de 1805, o leg. 732. Carta de Alessandro Paoletti a Antonio Vargas y Laguna de 13 de febrero de 1806 .

40 Así, en la detención del mercante de cuadros Rafael Anglá, acusado de violar a su sirvienta Maria Budoni, de trece años de edad, asistió el cónsul Gregorio Balducci por encargo del embajador, recomendándosele que registrara sus papeles y sustrajera -en caso de poseerla-cualquier licencia o patente real. AMAE. ss. leg. 781. Exp. 6. Carta del arzobispo Di Filippi a Antonio Vargas y Laguna de 16 de enero de 1802. 
—Desde luego, pero es algo que no se niega.

- ¿Y qué es lo que se hace si la persona a quien se busca está bajo su protección?

—Entonces Su Eminencia la hace avisar ${ }^{41}$.

La atención del jefe de la policía papal recaía sobre una pareja de amantes conocidos de Casanova que se hospedaban en la Plaza de España a la espera de emprender la fuga de los Estados Pontificios; circundados de alguaciles, ella, disfrazada de novicio, se había introducido en las habitaciones del aventurero veneciano. La denuncia de un espía apostado cerca de la sede de la embajada motivó que el cardenal vicario exigiese la entrega de la muchacha, quien sin embargo, secundada por Casanova, persuadió a Acquaviva de que la amparase, sustrayéndose así a la justicia del Santo Padre ${ }^{42}$.

Como se ha señalado, los ministros plenipotenciarios de la monarquía española tuvieron que defender tenazmente sus privilegios en el distrito de la legación de las pretensiones de acotarlos de los franceses y del pontífice desde el siglo XVII. La jurisdicción española colindaba con la desarrollada por los establecimientos franceses, que a partir de la pendiente de Trinità dei Monti dominaban esa vertiente del Pincio desde los tiempos de Carlos VIII, además de la franja circunscrita por las vías de San Sebastianello, del Babuino, della Croce y delle Carrozee; pese a ello, la guardia del Palacio de España actuaba frecuentemente sobre el graderío que a partir de 1725 conducía a dicha iglesia, básicamente porque su pertenencia a una u otra jurisdicción no se había jamás resuelto ${ }^{43}$. La construcción de la majestuosa escalinata, obra de Francesco De Sanctis, no sólo enfrentó al cardenal Bentivoglio con el cardenal de Polignac, representante del soberano Luis XV, sino al embajador francés con el Gobierno de Benedicto XIII, a causa de que su inscripción conmemorativa, no obstante a registrar el nombre del sucesor del Rey Sol, no enunciaba que se hallase bajo la protección de Francia ${ }^{44}$ (Fig. 6). La escena internacional apuntaba entonces hacia un acercamiento de la Corte de Felipe $\mathrm{V}$ y el Imperio de los Asburgo, después del rechazo francés del matrimonio entre una infanta española y Luis XV, en tanto que éste se aproximaba políticamente a Inglaterra y Prusia en el tratado de Hanover (1725). En este contexto de intereses encontrados entre Francia y España Benedicto XIII, representa-

41 Casanova, G., Memorias, Madrid, 1982, tomo I, p. 313.

42 Este tipo de acontecimientos se repiten recurrentemente en el siglo XVIII: en 1735 la hija de un hombre acaudalado se refugió con su amante en la hostería de la Barcaccia, que ya mencionamos se situaba en las proximidades de la Plaza de España. El padre informó a Acquaviva de todos estos hechos, y el cardenal ordenó conducir a la fugitiva a la iglesia de San Andrea della Frate, donde la mantuvo hasta que el cardenal vicario otorgó la licencia de matrimonio. VALEsio, F., Diario..., vol. V, p. 786.

43 Acerca de la escalinata, PecchiAl, P., La scalinata di Piazza di Spagna e Villa Medici, Roma, 1941; FERrARI, A., I viventi diritti dell'Italia a Palazzo Farnese, alla Scalinata ed alla Trinità de' Monti in Roma, Roma, 1965.

44 Anselmi, A., «\|l quartiere...», pp. 183 y 184. Consúltese la mencionada inscripción en el Diario Ordinario Chracas, 1203, 21-4-1725. 


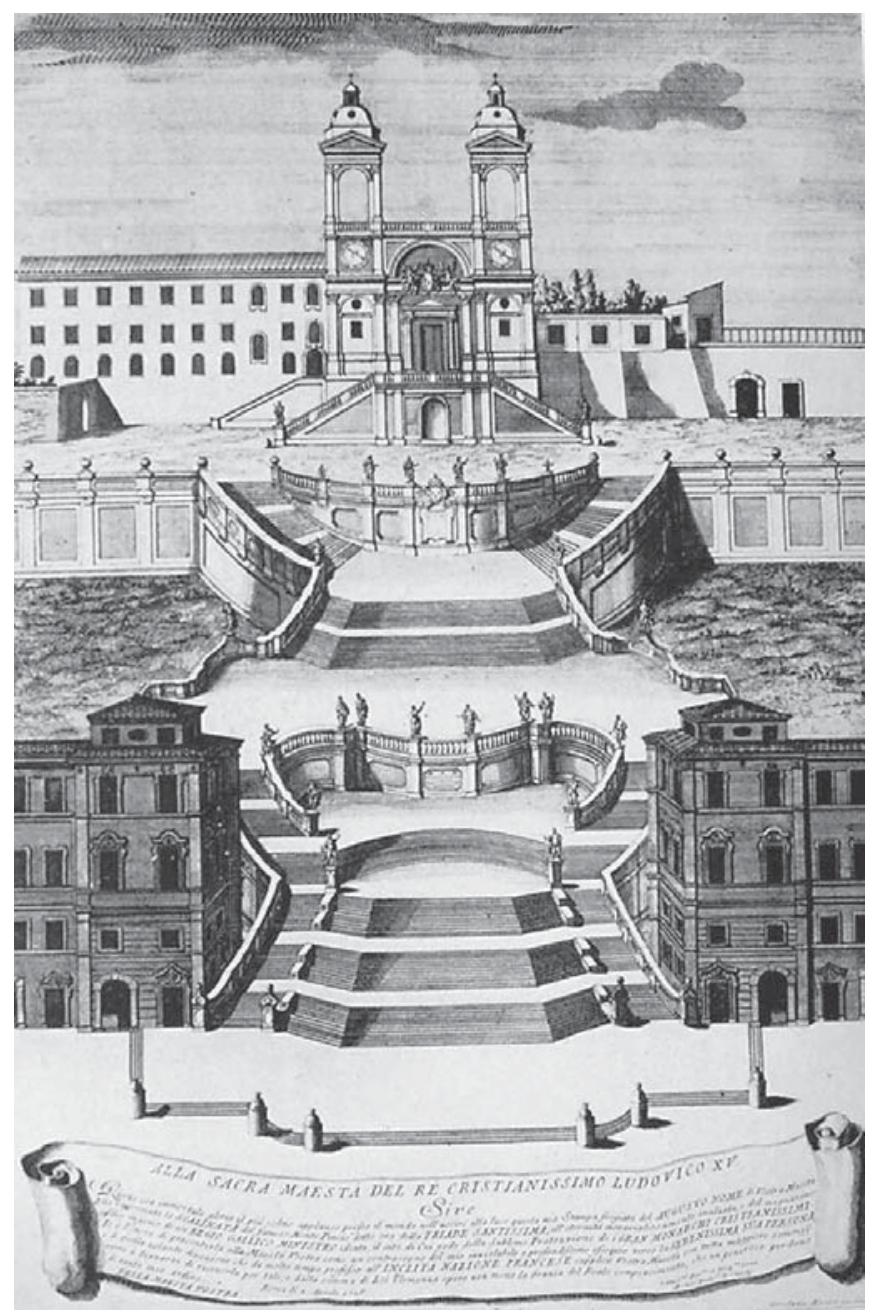

Fig. 6. Girolamo Rossi, Escalinata de la Trinità dei Monti con la dedicatoria al rey de Francia, 1726

do por monseñor Banchieri, a la sazón gobernador de Roma, respaldó la posición española conviniendo, de forma inaudita, que la embajada extendía su dominio territorial en el distrito de la Plaza de España, incluyendo la polémica escalinata, si bien ningún escrito dejó reflejado el acuerdo. Un plano del arquitecto Antonio Canevari, siempre de 1725, fijaba los dilatados términos del franco; además de las copias que quedaron en poder de la Santa Sede, una fue enviada a Madrid, mientras que el capitán de la guardia de palacio recibió otra para que en el desempeño de sus funciones no transgrediera esos límites ${ }^{45}$ (Fig. 7). En 1727 Bentivoglio transmitía al marqués de la Paz que Polignac aceptaba los argumentos que referidos a la escalinata había a favor de España, y que si retomaba la cuestión le aclararía cada una de sus dudas, insistiendo, como siempre, en que el único paliativo a que despertaran las ambiciones de mermar el franco recaía en la moderación de los guardias de palacio, y en que contuvieran su «incauta arrogancia». En la escalinata se reunían personas ociosas y desocupadas, sobre todo en verano, convirtiéndo-

45 Anselmi, A., «ll quartiere...», fig. 15. 


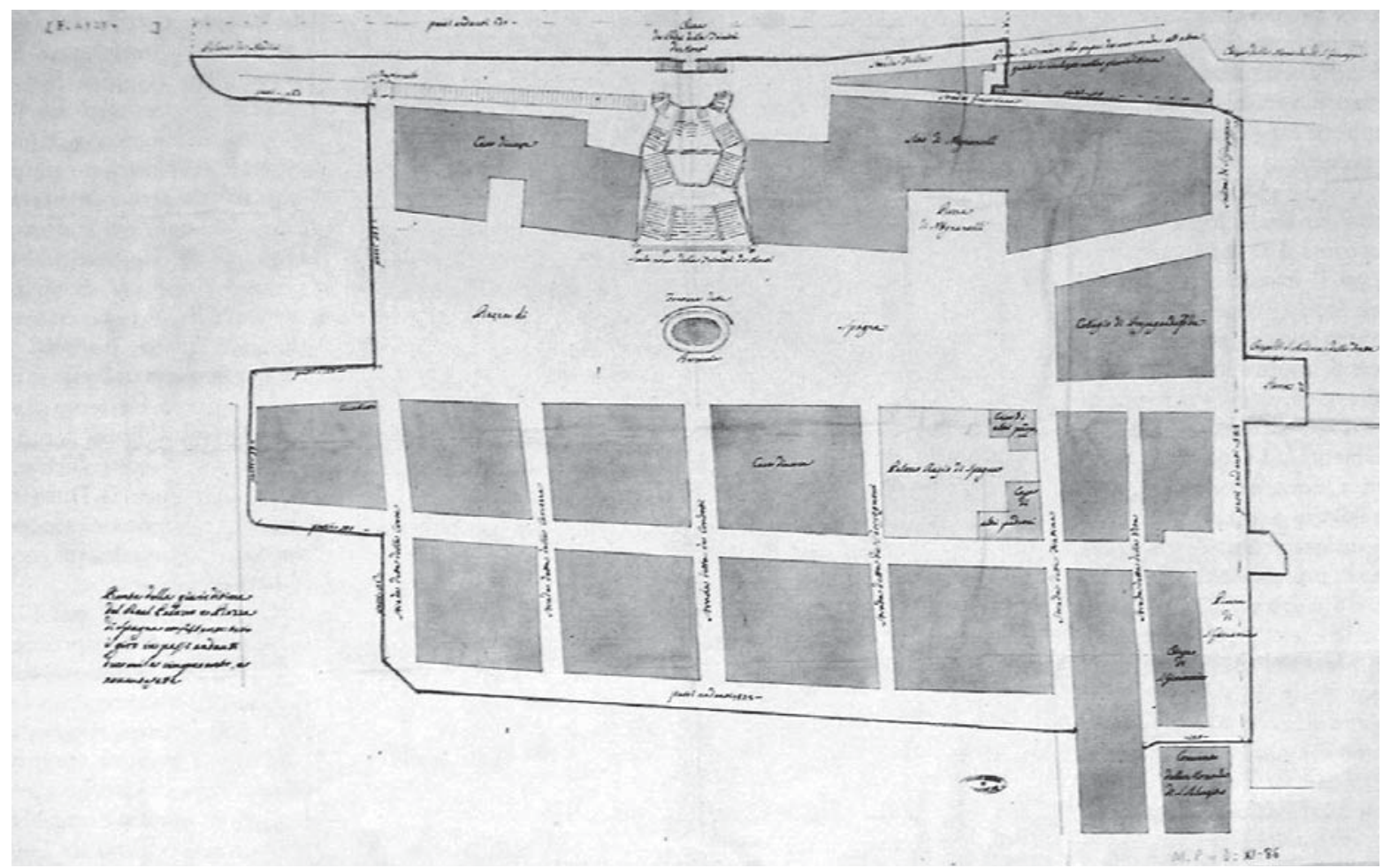

Fig. 7. Antonio Canevari, Pianta della giurisdizione del Real Palazzo e Piazza di Spagna, 1725, Archivo General de Simancas

la en un lugar peligroso en las horas nocturnas, razón por la cual el cardenal Belluga había propuesto en 1726 que se cerrara por la noche con rastrillos en sus accesos superior e inferior para evitar escándalos, consignando las llaves a los frailes de la Trinidad. La idea fue en un principio bien acogida, encomendándose a Bentivoglio que proporcionara 1.500 escudos a la Cámara Apostólica, a fin de que ésta instalara los enrejados ${ }^{46}$. Antes de cumplir con los deseos reales, el embajador, que no albergaba un especial afecto por el cardenal Belluga, expuso los inconvenientes de los que adolecía el proyecto: en primer lugar, siendo los religiosos de Trinità dei Monti de nacionalidad francesa, su ministro plenipotenciario dispondría del paso por las escaleras a su arbitrio, e incluso se apropiaría de las llaves, perjudicando a las autoridades españolas; y en segundo lugar, a pesar de costear la Corona los gastos de levantar esa cancela, al llevarlo a cabo la Cámara Apostólica parecería que el Papa se hubiese enseñoreado de ella, lo que también redundaría en prejuicio de la jurisdicción. Por lo tanto desaconsejaba la ejecución del plan y animaba a que se dejara a su dictamen la resolución de los desórdenes que se produjeran, promoviendo todas estas advertencias que se rechazara finalmente la proposición de Belluga.

Veinte años después de estos acontecimientos se reavivó la cuestión del convenio de monseñor Banchieri, cuya existencia fue siempre negada por él mis-

46 AMAE. ss. leg. 290. Carta del cardenal Bentivoglio al marqués de la Paz de 22 de marzo de 1727. 
$\mathrm{mo}^{47}$. En el verano de 1747 un esbirro había sufrido las rudas atenciones de un soldado de la legación al atravesar a caballo la jurisdicción; Alfonso Clemente de Aróstegui, disculpándose ante el secretario de Estado y el Papa, quienes alegaban que aquél era forastero, y desconocía las calles de Roma, inmediatamente sancionaba al guardia. Contemporáneamente otros esbirros penetraban disfrazados en la Plaza de España resueltos a aplicar la justicia en nombre del pontífice, hecho que Benedicto XIV se negó a reconocer hasta que el embajador no denunciase a los supuestos testigos de esta vulneración, lo cual no sucedió. A fin de evitar que en el futuro se repitiese esto, una real orden de Fernando VI dictaminaba que se ejecutase una planta del barrio al que se circunscribía la potestad de sus ministros, que Aróstegui encomendó a Ferdinando Fuga. El embajador interino además examinaba la documentación conservada en el archivo del palacio relativa a la franquicia, sin obtener grandes resultados, pues como ya indicamos, las dependencias que lo albergaban habían ardido en 1738. Fruto de sus pesquisas es un informe que remitió al ministro de Estado José de Carvajal y Lancaster, que nos revela cómo Banchieri y los papas sucesivos no admitieron la veracidad de lo estipulado en 1725, y en efecto, ningún convenio firmado lo demostraba, y las plantas de Canevari, igualmente sin rúbrica, carecían de valor legitimador ${ }^{48}$. Benedicto XIV atribuía al capitán de la guardia y al barrichelo de aquellos años la responsabilidad de que se hubiese delineado la planta, seguramente con el conocimiento de Banchieri, por lo que de ninguna manera los citados planos podían perjudicar sus derechos territoriales y su soberanía dentro de la capital de los Estados Pontificios. El rey, a la vista del escrito de su embajador, advertía que no se tolerase la entrada de esbirros en el quartiere, pero sin recurrir a distribuir bastonazos indiscriminadamente, y sobre todo resolvía «que no se piense en ningun caso en restringir ni limitar el franco, ni se acuerde ninguna concordia, y que tenga gentes de verdad, honor, y justificación, que le guarden, y defiendan con cordura y regla. Que aunque faltasen las razones, sobran las costumbres, mayormente estando toleradas con la practica de los demas embajadores de la Corona ${ }^{49}$. De nuevo una planta de la zona de la Plaza de España habría de reclamar la atención del soberano español sobre la situación del Forum Hispanicum en 1766, cuando el Gobierno pontificio exigió al grabador Giuseppe Vasi que rectificase del volumen explicativo del plano la atribución a Carlos III de la soberanía del área de la jurisdicción ${ }^{50}$ (Fig. 8). El trabajo

47 Antonio Banchieri (1667-1733), emparentado con la familia de Clemente XI, había ocupado el cargo de secretario de Consulta en 1712 y en 1724 sustituyó a monseñor Falconieri como gobernador de Roma. En 1726 Benedicto XIII lo nombró cardenal. PASTOR, L. V., Storia dei Papi, XV, Roma, 1933; AA.VV., Dizionario biografico degli italiani, Roma, 1963, tomo V, pp. 654 y 655.

$48 \mathrm{El}$ informe se localiza en AMAE. ss. leg. 310. Carta de Alfonso Clemente de Aróstegui a José de Carvajal y Lancaster de 31 de agosto de 1747.

49 AMAE. ss. leg. 196. Carta de José de Carvajal y Lancaster a Alfonso Clemente de Aróstegui de 30 de septiembre de 1747.

50 El texto de Vasi era el siguiente: «Dopo la divisata strada si slarga la magnifica piazza, che dicesi di Spagna non solo per il palazzo dell'Imbasciatore di quel Monarca; ma ancora perchè è di giurisdizione del medesimo, e perciò è la più frequentata a abitata da' forestieri, e illustri viaggiatori». VASI, G., Indice Istorico del gran prospetto di Roma dedicato alla sagra Maestà Cattolica di Carlo III re delle 
del grabador siciliano no era más que un claro instrumento propagandístico promovido y subvencionado por el monarca Borbón, a quien en consecuencia Vasi dedicaba la vista de la ciudad, tomada desde el monte Gianicolo, y alterar los términos empleados habría menoscabado los derechos que Carlos III mantenía en el franco. Así, ordenó a Tomás Azpuru (al frente de la embajada entre 1765 y 1771) que adquiriese todos los ejemplares de Vasi con el pretexto de hallarse dedicados a su persona, y que custodiados en el archivo del Palacio de España, se fuesen haciendo circular como si se encontrasen a la venta ${ }^{51}$. La administración papal, a través del maestro del Sacro Palacio, se apoderó no obstante de cincuenta y cuatro volúmenes, a los que añadió una serie de correcciones con las que Vasi tendría que sustituir el texto anterior, que Carlos III se disponía a aprobar solamente en el caso de que la palabra «jurisdicción» se cambiase por la de «territorio franco ó exento perteneciente á S.M.»52. De nuevo este conjunto de ejemplares que contenían las últimas modificaciones fueron comprados por Azpuru a Vasi y guardados en el archivo, lo cual no

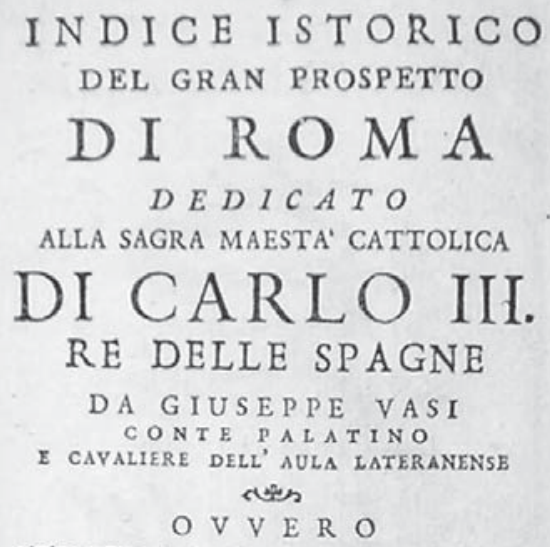
Con Licenza dé Superiori

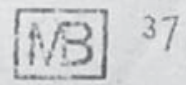

Fig. 8. Giuseppe Vasi, Indice Istorico del gran prospetto di Roma..., 1765 evitó que unas cuantas copias corregidas se distribuyeran por Roma, que Carlos III, decidido a no dar mayor publicidad al asunto, prefirió no requisar. La que nosotros hemos consultado apunta el privilegio español, pero en la edición de 1819, que el hijo del autor, Mariano Vasi, amplió con la descripción del Reino de Nápoles (y ahora con el nombre de la duquesa de Devonshire en la dedicatoria del tercer volumen), ya se suprimía dicha referencia ${ }^{53}$. En menos de medio siglo España habría de renunciar a un derecho de inmunidad nacido en la Roma de los papas, que en una ciudad a las puertas de integrarse en un

Spagne... ovvero itinerario istruttivo per ritrovare con facilità tutte le antiche e moderne magnificenze di Roma, con una breve disgressione sopra alcune Città e Castelli Suburbani, Roma, 1765, pp. 114 y 115 , n. ${ }^{\circ} 96$.

51 El número de volúmenes comprados por Azpuru se elevaba a 140, dos docenas de los cuales fueron expedidos a Madrid. AMAE. ss. leg. 215. Carta de Tomás Azpuru al marqués de Grimaldi de 24 de junio de 1766.

52 íbidem. Carta de Tomás Azpuru al marqués de Grimaldi de 1 de julio de 1766.

53 VASI, M., Itinerario istruttivo di Roma antica e moderna ovvero descrizione generale de' monumenti antichi e moderni, e delle opere le più insigni di pittura, scultura, ed architettura di questa alma città e delle sue vicinanze, Roma, 1819, vol. I, p. 235. 
Estado nacional, y de convertirse en su capital, había perdido todo su sentido. En el intervalo de ocupación de la Francia revolucionaria (1798-1799), un edicto del general Berthier suspendía el derecho de asilo en las iglesias, la jurisdicción civil y criminal de los embajadores y todos los privilegios de las embajadas y los establecimientos extranjeros. Con el reinado de José I Bonaparte en España el palacio de la legación pasó a ser cuartel general de las tropas francesas en Roma, por lo que el franco carecía de significado en una ciudad enteramente controlada por la administración napoleónica. A pesar de su anacrónica supervivencia durante la primera mitad del siglo XIX, persistió hasta la proclamación de la República Romana en 1849, tras cuyo fracaso no volvió a entrar en vigor ${ }^{54}$.

54 Romano, P., y Partini, P., Piazza..., p. 42. 